\title{
Rapid screening of pest resistance genes in maize using a sugarcane mosaic virus vector
}

Seung Ho Chung ${ }^{1}$, Mahdiyeh Bigham ${ }^{1}$, Ryan R. Lappe ${ }^{3}$, Barry Chan ${ }^{2}$, Ugrappa Nagalakshmi ${ }^{2}$, Steven A. Whitham ${ }^{3}$, Savithramma P. Dinesh-Kumar ${ }^{2}$, and Georg Jander ${ }^{1}$

${ }^{1}$ Boyce Thompson Institute for Plant Research, Ithaca, New York 14853

${ }^{2}$ Department of Plant Biology and The Genome Center, College of Biological Sciences, University of California, Davis, CA 95616

${ }^{3}$ Department of Plant Pathology and Microbiology, Iowa State University, Ames, Iowa 50011

\begin{abstract}
:
Spodoptera frugiperda (fall armyworm) is a notorious pest that threatens maize production world-wide. Current control measures involve the use of chemical insecticides and transgenic maize expressing Bacillus thuringiensis (Bt) toxins. Although several additional transgenes have confirmed insecticidal activity in other plants, limited research has been conducted in maize, at least partially due to the technical difficulty of maize transformation. Here, we describe implementation of a sugarcane mosaic virus (SCMV) vector for rapidly testing the efficacy of transgenes for the control of $S$. frugiperda in maize. Four categories of proteins were tested using the SCMV vector: (i) maize defense signaling proteins: peptide elicitors (Pep1 and Pep3) and jasmonate acid conjugating enzymes (JAR1a and JAR1b); (ii) maize defensive proteins: the previously identified ribosome-inactivating protein (RIP2) and maize proteinase inhibitor (MPI), and two proteins with predicted but unconfirmed anti-insect activities, an antimicrobial peptide (AMP) and a lectin (JAC1); (iii) lectins from other plant species: Allium cepa agglutinin (ACA) and Galanthus nivalis agglutinin (GNA); and (iv) spider and scorpion toxins: peptides from Urodacus yaschenkoi (UyCT3 and UyCT5) and Hadronyche versuta (Hvt). In most cases, $S$. frugiperda larval growth on maize was reduced by transient SCMV-mediated overexpression of genes encoding these proteins. Additionally, experiments with some of the SCMV-expressed genes showed effectiveness against two aphid species, Rhopalosiphum maidis (corn leaf aphid) and Myzus persicae (green peach aphid). Together, these results demonstrate that SCMV vectors can be exploited as a rapid screening method for testing the efficacy and insecticidal activity of candidate genes in maize.
\end{abstract}

\section{Keywords:}

Maize, Zea mays, Spodoptera frugiperda, fall armyworm, Rhopalosiphum maidis, Myzus persicae, sugarcane mosaic virus, peptide elicitors, venom toxins, lectins 


\section{Introduction:}

Maize (Zea mays) is one of the world's most important cereal crops, serving not only as a food source for humans and livestock, but also as a raw material for the production of ethanol and other industrial products (Ai and Jane, 2016; Chaudhary et al., 2014). The needs of an everexpanding population will lead to increasing demands on maize production in the coming years. Therefore, maintaining adequate maize yields will require reducing not only reducing the cost of agricultural inputs, but also the negative impacts of biotic and abiotic stresses that that limit maize productivity.

More than 100 species of insect pests limit maize productivity in agricultural fields (McMullen et al., 2009; Meihls et al., 2012). Among these pests, one of the most damaging is Spodoptera frugiperda (fall armyworm; Figure 1a), a lepidopteran species that is indigenous to the Americas but recently has become invasive in Africa and Asia (Food and Agriculture Organization of the United Nations, 2018; Goergen et al., 2016). By consuming all aboveground plant parts, $S$. frugiperda larvae reduce photosynthetic area, cause developmental delays, and decrease yield.

Currently available $S$. frugiperda control methods, both application of chemical insecticides (Togola et al., 2018) and transgenic maize producing Bacillus thuringiensis (Bt) toxins (Huang et al., 2014; Tabashnik and Carrière, 2017), are becoming less effective as the insects develop resistance. Therefore, there is a need to screen for additional transgenes that can be used to enhance maize resistance to $S$. frugiperda feeding. Broadly, such approaches can include upregulation of maize defense signaling, overexpression of individual maize defensive proteins, and expression of exogenous insecticidal proteins.

Plant elicitor peptides (Peps) trigger anti-herbivore defense responses (Huffaker, 2015; Huffaker et al., 2013; Poretsky et al., 2020). In maize, ZmPep1 and ZmPep3 upregulate defenses, at least in part by induction of the jasmonic acid (JA) signaling pathway (Huffaker et al., 2013, 2011). A key step in the JA pathway is the conjugation of JA with isoleucine by JAR1 (JASMONATE RESISTANT 1) enzymes (Koo and Howe, 2009; Staswick et al., 2002) to form JA-isoleucine. Expression of JARla and JARlb, two of the five predicted JAR genes in maize (Borrego and Kolomiets, 2016), is highly induced by Spodoptera exigua (beet armyworm) herbivory (Tzin et al., 2017). Thus, these maize genes are good targets for overexpression to enhance resistance against $S$. frugiperda.

Maize and other plants produce ribosome-inactivating proteins (RIPs) that block ribosome function by depurinating a specific adenine residue of the large ribosomal RNA (Bass et al., 2004; Zhu et al., 2018). These proteins, which are toxic for a variety of insects, including Lepidoptera (Shahidi-Noghabi et al., 2009) and Hemiptera (Hamshou et al., 2016), have been used previously in transgenic approaches. For instance, the expression of a maize kernel RIP1 in Nicotiana tabacum (tobacco) increased resistance to Helicoverpa zea (corn earworm) feeding (Dowd et al., 2003). The RIP2 gene is expressed in all maize tissues except the kernels (Bass et al., 2004). RIP2 expression was induced by $S$. frugiperda herbivory and recombinant RIP2 protein decreased caterpillar growth on artificial diet (Chuang, Herde, et al., 2014).

Two additional classes of maize proteins with anti-herbivore activity are proteinase inhibitors and antimicrobial peptides (Campos et al., 2018; Koiwa et al., 1997). Proteinase inhibitors, which are produced by many plant families, impair the growth and survival of insects by disrupting the function of digestive enzymes. Maize proteinase inhibitor $(M P I)$ expression was induced by both caterpillar herbivory and JA signaling (Cordero et al., 1994; Shivaji et al., 2010; Tamayo et al., 2000). Heterologous expression of MPI in rice increased resistance to Chilo 
suppressalis (striped stem borer) (Vila et al., 2005). Cyclotides are macrocyclic insecticidal peptides with the length of about 30 amino acids and a conserved cystine knot motif containing three disulfide bonds (Campos et al., 2018; Craik et al., 1999; Weidmann and Craik, 2016). Cyclotide Kalata B1 from Oldenlandia affinis decreased the growth of Helicoverpa armigera (corn earworm) larvae by rupturing epithelial cells in the midgut (Barbeta et al., 2008). Cycloviolacins, cyclotides from Viola odorata, negatively affected the probing and feeding behavior of Mysus persicae (green peach aphid), suggesting that cycloviolacins limit aphid population growth (Dancewicz et al., 2020). Among predicted antimicrobial peptides in maize, a few belong to the cyclotide family (Mulvenna et al., 2006; Noonan et al., 2017), but their efficacy against insects has not been confirmed.

Plant lectins, carbohydrate-binding proteins that interact with glycoproteins and glycan structures in insect guts, have antinutritional or insecticidal effects (Macedo et al., 2015). For instance, snowdrop lectin (Galanthus nivalis agglutinin; GNA), onion lectin (Allium cepa agglutinin; ACA) and garlic (Allium sativum) leaf lectin reduce nutrient uptake and growth in wide range of insects (Vandenborre et al., 2011). Expression of a maize lectin gene, Jacalin 1 $(J A C 1)$, is induced by $\mathrm{JA}$, an indication that it may provide protection against herbivory (Van Damme et al., 2004). There can be additive or even synergistic effects if lectins are co-expressed or fused to scorpion or spider venom peptides. For instance, the insecticidal efficacy of GNA was increased by fusions to Hvt (Fitches et al., 2012), ButaIT from Mesobuthus tamulus (Fitches et al., 2010), AaIT from Androctonus australis (Liu et al., 2016), and $\delta$-amaurobitoxin-PIla from Pireneitega luctuosus (Yang et al., 2014).

Scorpion and spider venoms, which contain numerous insecticidal toxins (King and Hardy, 2013; Ortiz et al., 2015), have been explored as sources of insecticidal peptides. UyCT3 and UyCT5, two antimicrobial peptides that are produced in the venom glands of Urodacus yaschenkoi (inland robust scorpion) decrease the fitness of Acyrthosiphon pisum (pea aphid) and the density of the primary symbiont, Buchnera aphidicola, suggesting that those are promising candidates for the production of insect-resistant transgenic plants (Luna-Ramirez et al., 2017). Similarly, $\omega$-hexatoxin Hvla (Hvt, also called $\omega$-ACTX Hvla) from Hadronyche versuta (Blue Mountains funnel web spider) is broadly effective against both lepidopteran and hemipteran pests when expressed in transgenic plants (Javaid et al., 2016; Ullah et al., 2015; Rauf et al., 2019). Given the broad insecticidal activity of these spider and scorpion venom proteins, we hypothesized that they would also be effective in reducing $S$. frugiperda growth.

Testing the effectiveness of transgenes for controlling pest insects on maize is limited by the high cost of maize transformation and the often greater than one-year timeline that is required to obtain transgenic maize plants for experiments. Therefore, we are proposing an alternate approach, whereby the efficacy of transgenes that enhance maize pest tolerance is tested by transient expression in maize using a virus vector. Sugarcane mosaic virus (SCMV), a positivesense single-stranded RNA virus, which has been adapted for efficient transgene expression in maize (Mei et al., 2019), is attractive vector for such experiments. Genes of interest are inserted between the SCMV P1 and HC-Pro cistrons in SCMV-CS3, a newly created plasmid vector, maize seedlings are infected by particle bombardment or Agrobacterium inoculation, and the pest resistance of the infected plants can be assessed after three weeks. Here we show that virusmediated expression of maize defense-regulating proteins, maize insecticidal proteins, and exogenous toxins can reduce the growth of insect pests. We demonstrate the insect-controlling properties of not only known proteins but also two maize proteins that were not previously confirmed to have anti-herbivore properties. Furthermore, we show that expression of transgenes 
using SCMV also is effective in reducing production by two hemipteran pests, Rhopalosiphum maidis (corn leaf aphid; Figure 1b) and M. persicae (Figure 1c).

\section{Materials and methods}

\section{Plants and insects}

Maize (Zea mays) plants, sweet corn variety Golden Bantam (West Coast Seeds, British Columbia, Canada) and inbred lines P39 and B73, were grown in a maize mix $\left[0.16 \mathrm{~m}^{3}\right.$ MetroMix 360 (Scotts, Marysville, OH, USA), $0.45 \mathrm{~kg}$ finely ground lime, $0.45 \mathrm{~kg}$ Peters Unimix (Griffin Greenhouse Supplies, Auburn, NY, USA), 68 kg Turface MVP (Banfield-Baker Corp., Horseheads, NY, USA), $23 \mathrm{~kg}$ coarse quartz sand, and $0.018 \mathrm{~m}^{3}$ pasteurized field soil]. All plants, including those used for SCMV propagation and insect bioassays, were maintained in a growth chamber at $23^{\circ} \mathrm{C}$ with a $16: 8$ light:dark cycle. Unless specified otherwise, Golden Bantam maize was used for the described experiments.

Eggs of S. frugiperda (fall armyworm) were purchased from Benzon Research (Carlisle, PA, USA) and maintained on an artificial diet (Fall Armyworm Diet, Southland Products Inc, Lake Village, AR, USA) in an incubator at $28^{\circ} \mathrm{C}$. A colony of a genome-sequenced $R$. maidis lineage (W. Chen et al., 2019) was maintained on maize (Golden Bantam or P39) and a colony of a previously described tobacco-adapted strain of $M$. persicae (Ramsey et al., 2007) was maintained on Nicotiana tabacum (tobacco) at $23^{\circ} \mathrm{C}$ under $16: 8$ light:dark cycle. Both $R$. maidis and $M$. persicae were originally collected in USDA-ARS greenhouses by Steward Gray (Robert W. Holley Center for Agriculture \& Health, Ithaca, NY, USA).

\section{Cloning of candidate genes into Sugarcane mosaic virus for protein expression}

The pSCMV-CS3 expression vector used in this work was derived from pSCMV-CS2 (Mei et al., 2019), which was modified to contain the CS3 restriction sites in the MCS between the P1 and HC-Pro cistrons (Figure 2a). The modified pSCMV-CS2 genome plus the flanking 35S promoter and NOS terminator was amplified with SuperFi polymerase (ThermoFisher Scientific, Waltham, MA) using primers DCPacI $1380 \mathrm{~F}$ and DCPacI $1380 \mathrm{R}$ (Supplementary Table S1). The pCAMBIA1380 backbone (www.cambia.org) was amplified with SuperFi polymerase using primers 1380F and 1380R (Supplementary Table S1). The two PCR fragments were subsequently assembled into pCAMBIA1380-SCMV-CS3, hereafter referred to as pSCMV-CS3, by Gibson Assembly (New England Biolabs, Ipswich, MA). pSCMV-GFP was created by amplifying the mEGFP coding sequence (Zacharias et al., 2002) using SuperFi polymerase with the GFP-Psp and GFP-SbfI primers (Supplementary Table S1). The resulting amplicon was digested with $P s p \mathrm{OMI}$ and $S b f$, gel purified and ligated into similarly digested pSCMV-CS3.

Genes encoding maize defense regulators and protein toxins were amplified from the B73 cDNA template with gene-specific primers containing restriction sites at the 5 ' end for cloning into SCMV vector. PCR products were gel purified, digested with the corresponding restriction enzymes and cloned into the SCMV vector (Figure 2a). The UyCT3 and UyCT5 genes (codon optimized for maize), as well as the maize Pep1 and Pep3 genes, were synthesized by Genscript Biotech (Piscataway, NJ, USA) and cloned into the SCMV vector. To generate SCMV with $H v t$, $A C A, G N A, R I P 2, H v t-A C A, H v t^{*}-A C A, R I P 2-G N A$, and $H v t-G N A$, primers listed in Supplementary Table S1 and DNA synthesized by Genewiz (South Plainfield, NJ, USA) were used as template and the resulting PCR products were gel purified and cloned into PspOMI-SbfI cut SCMV by following the NEBuilder HiFi DNA Assembly method (NEB, Ipswich, MA, 
USA). Primers, restriction sites, and cloning methods used in this study are listed in Supplementary Table S1.

\section{Inoculation of maize with SCMV constructs}

SCMV constructs were delivered into maize plants by particle bombardment using a Biolistic PDS-1000/He system (Bio-Rad, Hercules, CA, USA) as described previously (Mei and Whitham, 2018). One $\mu \mathrm{g}$ of the plasmid DNA was coated on $3 \mathrm{mg} 1.0 \mu \mathrm{m}$ diameter gold particles, and the coated gold particles were distributed onto five microcarriers and allowed to air dry. Plants were placed in the dark $12 \mathrm{~h}$ before the particle bombardment. Two leaves of oneweek-old plants were bombarded with using 1,100 psi rupture disks at a distance of $6 \mathrm{~cm}$ (between stopping screen and leaves).

Agroinoculation was used to initiate maize infections with the SCMV constructs containing Hvt, ACA, and $U y C T 3$. The constructs were transformed into the Agrobacterium tumefaciens strain GV3101 and an A. tumefaciens suspension with optical density at $600 \mathrm{~nm}$ $\left(\mathrm{OD}_{600}\right)=1.0$ in infiltration buffer $(200 \mu \mathrm{M}$ acetosyringone, $10 \mathrm{mM}$ MES, pH 5.6, and $10 \mathrm{mM}$ $\mathrm{MgCl}_{2}$ ) was injected above the coleoptile node of one-week-old plants.

After the initial infection by particle bombardment or Agroinoculation, SCMV constructs were further propagated by rub-inoculation. Leaf sap of SCMV-infected plants was prepared by grinding $0.5 \mathrm{~g}$ leaf tissue in $5 \mathrm{ml}$ of $50 \mathrm{mM} \mathrm{pH} 7.0$ potassium phosphate buffer. One-week-old maize plants were dusted with 600 -mesh carborundum and mechanically inoculated by rubbing leaf sap from virus-infected maize plants on two leaves.

\section{Confocal microscopy}

Three weeks post-inoculation, leaf samples were collected from the seventh or eighth leaves of maize plants infected with SCMV-GFP. The samples were observed at an excitation of $488 \mathrm{~nm}$. The emitted fluorescence signal was monitored from 505 to $545 \mathrm{~nm}$ using a SP5 Leica Confocal Microscope in the Plant Cell Imaging Center of Boyce Thompson Institute. A scan of fluorescence across a range of wavelengths (lambda scan) was used to confirm that the observed signal was derived from GFP rather than endogenous maize fluorescence.

\section{Insect bioassays}

To determine the effect of defensive proteins on the growth of S. frugiperda, SCMV-infected plants, three weeks post-inoculation, were used for caterpillar bioassays. Five two-day-old caterpillars were placed on each plant and enclosed using perforated plastic bags $(13 \mathrm{~cm} \times 61$ $\mathrm{cm}$, https://www.clearbags.com). The caterpillar fresh mass was measured one week later. For aphid bioassays, eight 10-day-old apterous adult $R$. maidis or ten 10-day-old apterous adult $M$. persicae were placed on each virus-infected plant 15-18 days after SCMV inoculation and enclosed using perforated plastic bags. The total numbers of aphids were counted one week later.

\section{RNA extraction, cDNA synthesis, RT-PCR, and quantitative real-time PCR (qRT-PCR)}

Three weeks post-inoculation and prior to the insect bioassays, leaf tissue was collected from the seventh or eighth leaves of infected plants, flash-frozen in liquid nitrogen, and stored at $-80{ }^{\circ} \mathrm{C}$. RNA was extracted using TRIzoL Reagent (Invitrogen, Carlsbad, CA, USA) and treated with RQ1 RNase-free DNase (Promega, Madison, WI, USA). One microgram of RNA was used to synthesize first-strand cDNA using High-Capacity cDNA Reverse Transcription Kit (Applied Biosystems, Foster City, CA, USA) with random primers. To verify the expression of insect 
resistance genes cloned into the SCMV vector, qRT-PCR was conducted with gene-specific primers (Supplementary Table S1). For the inserts of less than $75 \mathrm{bp}$ (Pep1, Pep3, UyCT3, and UyCT5), one primer was designed to bind to the insert and another primer was designed to bind to the region flanking the cloning site, with the amplification products ranging in size from 100$150 \mathrm{bp}$. The reactions consisted of $5.0 \mu \mathrm{l}$ of the PowerUp SYBR Green PCR master mix (Applied Biosystems), $0.6 \mu \mathrm{l}$ primer mix (300 $\mathrm{nM}$ for the final concentration of each primer) and $2 \mu \mathrm{l}$ of cDNA (1:10 dilution with nuclease-free $\mathrm{H}_{2} \mathrm{O}$ ) in $10 \mu$ total volume. Template-free reactions were included as negative controls. The PCR amplification was performed on QuantStudio 6 Flex Real-Time PCR Systems (Applied Biosystems, Foster City, CA, USA) with the following conditions: $2 \mathrm{~min}$ at $50^{\circ} \mathrm{C}, 2 \mathrm{~min}$ at $95^{\circ} \mathrm{C}, 40$ cycles of $95^{\circ} \mathrm{C}$ for $15 \mathrm{sec}$ and $60^{\circ} \mathrm{C}$ for $1 \mathrm{~min}$. Primer specificity was confirmed by melting curve analysis. Mean cycle threshold values of duplicates of each sample were normalized using two reference genes, Actin and EF1$\alpha$. Relative gene expression values were calculated using $2^{-\Delta \Delta \mathrm{Ct}}$ method (Livak and Schmittgen, 2001).

\section{Statistical analysis}

All statistical analyses were conducted using R (R Core Team, 2017). Data for gene expression and larval mass of $S$. frugiperda larvae, and aphid fecundity were compared using analysis of variance (ANOVA) followed by Tukey's test or Dunnett's test relative to the GFP control or $t$ test. Gene expression data were $\log 2$ transformed before the statistical analysis to meet the assumptions of ANOVA but untransformed data are presented in the figures. Survival of $S$. frugiperda larvae was analyzed using non-parametric Kruskal-Wallis tests. Raw data underlying the bar graphs are presented in Supplemental Tables S2-S8.

\section{Results}

\section{SCMV-GFP does not affect $\boldsymbol{S}$. frugiperda growth on maize}

A previously described SCMV cloning vector (Mei et al., 2019) was modified to produce SCMV-CS3 (Figure 2a) and the mEGFP coding sequence (Zacharias et al., 2002) was placed in the multiple cloning site to produce SCMV-GFP. An empty vector control virus (SCMV-EV) and SCMV-GFP were used to inoculate one-week-old maize seedlings. Both SCMV-GFP and SCMV-EV caused mosaic symptoms within two weeks after inoculation and continued to spread in newly emerging leaves of the infected plants (Figure $2 \mathrm{~b}$ ). Three weeks post-inoculation, the GFP expression level was significantly higher in plants infected by SCMV-GFP than SCMV-EV (Figure 2c). Infected leaves were examined using confocal microscopy and the green fluorescence signal was only detected in leaves infected with SCMV-GFP (Figure 2d). Neither $S$. frugiperda larval survival (Figure 2e) nor larval growth (Figure 2f) differed significantly between plants infected by SCMV-GFP and SCMV-EV. SCMV-GFP was used as a transgeneexpressing virus control treatment in subsequent experiments to test the efficacy of insect growth-inhibiting proteins (Table 1) against $S$. frugiperda, R. maidis, and M. persicae (Figure 1ac).

\section{Expression of endogenous maize genes using SCMV enhances $\boldsymbol{S}$. frugiperda resistance} We cloned the 69 bp sequences of the maize Pepl and Pep3 defense elicitors (Huffaker et al., 2011, 2013) into pSCMV-CS3 and inoculated seedlings of sweet corn variety Golden Bantam. Pep1 and Pep3 expression was confirmed by qRT-PCR three weeks post-inoculation (Figure 3a,b). Relative to SCMV-GFP, infection with SCMV-Pep1 and SCMV-Pep3 caused increased 
transcript accumulation of maize proteinase inhibitor (MPI; Figure 3c), a JA pathway marker gene with antiherbivore activity (Chuang, Ray, et al., 2014). Pep1 and Pep3 expression decreased the growth of $S$. frugiperda larvae on Golden Bantam maize by $25 \%$ and $51 \%$, respectively, compared to GFP control plants (Figure 3d), but did not affect survival of the larvae (Table S4). Similar results were obtained for Pep3 using popcorn (P39) and field corn (B73) inbred lines (Figure 3e,f), showing that the effect on $S$. frugiperda growth is not specific to Golden Bantam.

We targeted previously investigated maize insect resistance genes (JARla, JAR $1 b, R I P 2$, and $M P I)$ and two predicted resistance genes ( $A M P$ and $J A C 1)$ for overexpression using SCMV. A previously uncharacterized gene (GRMZM2G032198) encoding a maize cyclotide antimicrobial peptides was designated as $A M P$. Expression of both $A M P$ and $J A C 1$ was induced by $S$. frugiperda herbivory (Figure S1), suggesting that these genes are involved in maize insect resistance. The expression levels of JAR $1 a$, JAR $1 b, R I P 2, J A C 1, A M P$, and MPI were significantly higher in plants infected by the corresponding SCMV constructs than in SCMVGFP control plants (Figure 3g-j,m,n). SCMV-JARl $a$ and SCMV-JARIb also significantly increased MPI expression (Figure 3k), confirming upregulation of JA-related defense pathways. More importantly, the growth of $S$. frugiperda larvae was up to $60 \%$ lower on plants expressing $J A R 1 a, J A R 1 b, R I P 2, J A C 1, A M P$, and MPI than on Golden Bantam control plants infected with SCMV-GFP (Figure 31,o).

\section{Expression of scorpion insecticidal proteins reduces $S$. frugiperda growth}

To determine whether SCMV can be used to express heterologous insect resistance genes in maize, we cloned $U y C T 3$ and $U y C T 5$, which encode $U$. yaschenkoi venom toxins, into the SCMV vector. Transgene expression in maize was confirmed by qRT-PCR (Figure 4a,b). Both SCMV-UyCT3 and SCMV-UyCT5 reduced S. frugiperda weight on P39 and B73 plants compared to SCMV-GFP control plants (Figure 4c,d).

\section{Expression of fusion proteins using SCMV has additive effects on $S$. frugiperda}

Fusion of spider and scorpion neurotoxins with plant lectins can improve their toxicity (Fitches et al., 2012; Liu et al., 2016; Rauf et al., 2019). We investigated this effect in maize using SCMV constructs. Because SCMV vectors produce a polyprotein precursor from which functional proteins are cleaved by the NIa protease (Mei et al., 2019), we generated SCMV constructs with and without an NIa cleave site between the venom toxin and lectin to determine whether the proteins are more efficacious separately or as fusion proteins. The expression levels of $H$. versuta toxin $(H v t)$ and $A$. cepa agglutinin $(A C A)$ genes were significantly higher in plants infected by each corresponding SCMV constructs than SCMV-GFP control (Figure 5a and 5b), and the presence of protease cleavage site between $H v t$ and $A C A$ did not affect $H v t$ and $A C A$ transcript accumulation. Expression of single proteins did not significantly decrease $S$. frugiperda growth relative to the GFP control (Figure 5c). However, the expression of fusion protein by SCMV-Hvt-ACA or two individual proteins of Hvt and ACA by SCMV-Hvt-cleavage site- $A C A$ reduced the larval growth by $39 \%$ and $46 \%$, relative to the GFP control (Figure $5 \mathrm{c}$ ), respectively, suggesting an additive effect from the expression the two genes.

As the presence of a cleavage site between the two protein components did not increase efficacy (Figure 5c), we tested insecticidal activity of fusion proteins without viral protease cleavage sites in subsequent experiments. SCMV constructs were made with a maize defense gene, RIP2, and a spider insecticidal protein, $H v t$, fused to G. nivalis agglutinin (GNA). We 
confirmed that each gene was expressed in plants infected by the corresponding construct (Figure 5d,e,g,h). Although the expression of GNA alone did not affect $S$. frugiperda larval growth, infection with SCMV-RIP2 and SCMV-RIP2-GNA reduced S. frugiperda growth by $28 \%$ and $27 \%$, respectively (Figure $5 \mathrm{f}$ ). In the case of $H v t$ and $G N A$, neither gene by itself significantly reduced caterpillar growth. However, the SCMV-Hvt-GNA fusion construct significantly decreased $S$. frugiperda larval growth compared to GFP control protein (Figure 5i). Together, these results indicate that fusion proteins combining lectins and maize defense proteins or venom toxins can improve resistance against $S$. frugiperda.

Expression of maize and scorpion genes enhances resistance to phloem-feeding herbivores To investigate whether our SCMV constructs also provide protection against phloem-feeding insects, we conducted aphid bioassays using P39 plants infected with a subset of the previously tested constructs: SCMV-GFP, SCMV-Pep3, SCMV-RIP2, SCMV-UyCT3, SCMV-UyCT5, $S C M V-A M P$, and SCMV-JAC1. GFP expression did not affect aphid numbers compared to the empty vector control (Figure 6a,b). By contrast, expression of maize defense proteins and scorpion toxins significantly decreased progeny production by both $R$. maidis (Figure 6a,c) and M. persicae (Figure 6b,d) compared to SCMV-GFP control.

\section{Discussion}

Artificial diet assays are commonly employed for testing the oral efficacy of novel insecticidal proteins against insect herbivores (Panwar et al., 2018; Yao et al., 2003; Fitches et al., 2012). However, growth inhibition on artificial diet does not always correlate well with the effects that are observed when the same insecticidal proteins are subsequently expressed in transgenic plants (Khan et al., 2020). Both the context of the surrounding plant tissue and the localization of the insecticidal proteins in the plants could affect their toxicity against insect herbivores. Therefore, rather than pre-screening insecticidal proteins by cloning in microbial systems, purification, and artificial diet assays, we propose that transient expression using a viral vector such as SCMV will be a more effective approach for rapidly testing the in planta efficacy of novel insecticidal proteins.

Reduced weight gain of $S$. frugiperda in response to SCMV-mediated expression of Pep1, Pep3, JARla, JAR1b, RIP2, MPI, UyCT3, and UyCT5 as single-gene constructs is consistent with previous reports of these genes providing protection against insect herbivory. Additionally, $A M P$ and $J A C 1$, two maize genes that are upregulated in response to $S$. frugiperda feeding (Figure S1), reduced caterpillar weight gain when overexpressed in maize. Although transcriptomic studies have identified numerous maize genes that are upregulated in response to arthropod feeding (Bui et al., 2018; Pan et al., 2020; Tzin et al., 2015, 2017; Yang et al., 2020; Guo et al., 2019; Song et al., 2017; Wang et al., 2017; Zhang et al., 2016), the majority of these genes have not been investigated for their role in plant defense against herbivory. This is at least in part due to the time and cost of creating maize lines that have individual genes overexpressed. Transient expression using SCMV, as we have done for $A M P$ and $J A C 1$, will accelerate the process of testing the defensing functions of maize genes that are induced in response to herbivory.

Although these genes increased resistance in other plant-insect studies (Liu et al., 2016; Ullah et al., 2015; Vandenborre et al., 2011), overexpression of $H v t, A C A$, and GNA as singlegene SCMV constructs in maize did not significantly reduce $S$. frugiperda weight gain. Nevertheless, expression of gene fusions, $H v t-A C A$ and $H v t-G N A$, reduced $S$. frugiperda weight 
gain, indicating that there are additive effects of the spider venom and the lectin (Figure 5c,i). This is consistent with other studies that the toxicity of spider and scorpion toxins was improved by combining with a lectin, which may facilitate the transfer of the venom proteins across the gut lumen (Fitches et al., 2002; Javaid et al., 2016; Nakasu et al., 2014; Rauf et al., 2019). In addition to these synergistic effects on larval growth, it is likely that the stacking of multiple toxic proteins with different modes of action in one viral construct will delay the development of resistance in insects (Head et al., 2017; Ni et al., 2017). In contrast to Hvt-lectin fusions, we did not observe an additive effect when RIP2 was linked to GNA (Figure 5f). This difference may be attributed to the differing origins of the toxin proteins expressed in the SCMV constructs. Whereas spider venoms like Hvt are injected directly into the hemolymph, the maize RIP2 protein would be consumed orally by lepidopteran larvae. As an endogenous maize insecticidal protein, RIP2 may bind to an as yet unknown receptor and thereby enter the midgut cells and/or the insect hemolymph. Thus, these results suggest that the fusion proteins of non-maize toxins and lectins enhance the insecticidal activity of the fusion protein.

Our observation of increased defense gene expression (Figure 3c) and reduced $S$. frugiperda weight gain (Figure 3d-f) on plants infected with SCMV-Pep1 and SCMV-Pep3, are consistent with experiments showing that pre-treatment of maize plants with Pep1 and Pep3 increases JA levels, defense gene expression, and defensive metabolites, leading to reduced growth of S. exigua larvae (Huffaker et al., 2011, 2013). Under normal circumstances, peptide signaling is initiated when plasma membranes are disrupted and elicitor peptides are released from the cytoplasm into the apoplastic space (Bartels and Boller, 2015). Receptors on neighboring intact cells recognize these peptides and elicit downstream defense pathways (Lori et al., 2015). However, in our experiments, the expression of MPI was induced in plants infected by SCMV-Pep1 and SCMV-Pep3, even before initiation of caterpillar feeding (Figure 3c). Pathogen attack can cause plant proteins without secretory signals to be released into apoplast (Agrawal et al., 2010), and is possible that SCMV infection initiated Pep1 and Pep 3 signaling in this manner

Induced defenses, in particular those regulated by the jasmonic acid pathway, typically are turned on after perception of insect herbivory by maize and other plants (Erb and Reymond, 2019; Howe and Jander, 2008). However, initiation of jasmonate-regulated defenses takes time and some lepidopteran herbivores may have the ability to suppress jasmonate signaling (C.-Y. Chen et al., 2019). Therefore, targeted initiation of maize defense responses by expression of regulatory proteins in SCMV may be an approach for increasing pest resistance. Such virusmediated induction could be deployed in maize fields when there is the specific threat of insect pests such as $S$. frugiperda.

Currently available insect-resistant transgenic maize varieties, in particular those expressing Cry, Cyt, or Vip genes from B. thuringiensis (Bravo et al., 2011; Chakroun et al., 2016), are not effective against phloem-feeding insects such as Rhopalosiphum maidis (corn leaf aphid; Figure 1b) or Myzus persicae (green peach aphid; Figure 1c). Although the toxicity of $B t$ toxins can be increased by incorporating peptide sequences that bind to aphid guts (Chougule $e t$ $a l ., 2013)$, this has not yet resulted in a commercially viable $B t$ toxin directed at hemipteran herbivores. Thus, there is an interest in identifying additional insecticidal proteins that can be expressed in the plant phloem to enhance aphid resistance. Our demonstration that transient expression of both endogenous maize proteins and insecticidal proteins from other species can reduce reproduction of $R$. maidis and $M$. persicae (Figure 6), suggests that SCMV-mediated 
overexpression can be used to rapidly screen proteins for their effectiveness against hemipteran pests of maize.

Our results demonstrate the utility of SCMV-mediated overexpression for screening the efficacy of proteins that reduce insect growth on maize plants. Virus-mediated transient expression assays included genes encoding maize regulatory proteins, endogenous maize defensive proteins, and non-maize insecticidal proteins. The main advantage of the SCMV overexpression system is a timeline that makes it possible to test the effectiveness of single- and multi-gene constructs in actual maize plants in only two months. Although the main focus of our efforts was a lepidopteran herbivore, S. frugiperda, we also showed efficacy of SCMV constructs against two aphid species, $R$. maidis and $M$. persicae, suggesting that the SCMV-mediated transient expression approach will be broadly useful for experiments with both chewing and piercing/sucking herbivores of maize.

\section{Acknowledgements}

We thank Mamta Srivastava for help with confocal microscopy. This work was supported by agreement HR0011-17-2-0053 from the Defense Advanced Research Projects Agency (DARPA) Insect Allies Program with the Boyce Thompson Institute. The views and conclusions contained in this document are those of the authors and should not be interpreted as representing the official policies, either expressed or implied, of DARPA or the US Government. The US Government is authorized to reproduce and distribute reprints for Government purposes notwithstanding any copyright notation hereon.

\section{Short legends for Supporting Material}

Supplementary Figure S1. Gene expression of $A M P$ and $J A C 1$ in P39 maize plants damaged by Spodoptera frugiperda caterpillars.

Supplementary Table S1. Primers used in this study.

Supplementary Table S2. Raw data for the graphs in Figure 2.

Supplementary Table S3. Raw data for the graphs in Figure 3.

Supplementary Table S4. Raw data for the graphs in Figure 4.

Supplementary Table S5. Raw data for the graphs in Figure 5.

Supplementary Table S6. Raw data for the graphs in Figure 6.

Supplementary Table S7. Raw data for the graphs in Figure S1. 


\section{References}

Agrawal, G.K., Jwa, N.-S., Lebrun, M.-H., Job, D., and Rakwal, R. (2010) Plant secretome: unlocking secrets of the secreted proteins. Proteomics, 10, 799-827.

Ai, Y. and Jane, J. (2016) Macronutrients in Corn and Human Nutrition. Comprehensive Reviews in Food Science and Food Safety, 15, 581-598.

Barbeta, B.L., Marshall, A.T., Gillon, A.D., Craik, D.J., and Anderson, M.A. (2008) Plant cyclotides disrupt epithelial cells in the midgut of lepidopteran larvae. Proc. Natl. Acad. Sci. U.S.A., 105, 1221-1225.

Bartels, S. and Boller, T. (2015) Quo vadis, Pep? Plant elicitor peptides at the crossroads of immunity, stress, and development. J. Exp. Bot., 66, 5183-5193.

Bass, H.W., Krawetz, J.E., OBrian, G.R., Zinselmeier, C., Habben, J.E., and Boston, R.S. (2004) Maize ribosome-inactivating proteins (RIPs) with distinct expression patterns have similar requirements for proenzyme activation. J. Exp. Bot., 55, 2219-2233.

Borrego, E.J. and Kolomiets, M.V. (2016) Synthesis and Functions of Jasmonates in Maize. Plants (Basel), 5.

Bravo, A., Likitvivatanavong, S., Gill, S.S., and Soberón, M. (2011) Bacillus thuringiensis: A story of a successful bioinsecticide. Insect Biochem Mol Biol, 41, 423-431.

Bui, H., Greenhalgh, R., Ruckert, A., Gill, G.S., Lee, S., Ramirez, R.A., and Clark, R.M. (2018) Generalist and specialist mite herbivores induce similar defense responses in maize and barley but differ in susceptibility to benzoxazinoids. Front Plant Sci, 9, 1222.

Campos, M.L., de Souza, C.M., de Oliveira, K.B.S., Dias, S.C., and Franco, O.L. (2018) The role of antimicrobial peptides in plant immunity. J. Exp. Bot., 69, 4997-5011.

Chakroun, M., Banyuls, N., Bel, Y., Escriche, B., and Ferré, J. (2016) Bacterial Vegetative Insecticidal Proteins (Vip) from Entomopathogenic Bacteria. Microbiol Mol Biol Rev, 80, 329-350.

Chaudhary, D. P., Kumar, S., and Yadav, O.P. (2014) Nutritive Value of Maize: Improvements, Applications and Constraints. In: Maize: Nutrition Dynamics and Novel Uses (Chaudhary,Dharam Paul, Kumar,S., and Langyan,S., eds), pp. 3-17. New Delhi: Springer India.

Chen, C.-Y., Liu, Y.-Q., Song, W.-M., Chen, D.-Y., Chen, F.-Y., Chen, Xue-Ying, et al. (2019) An effector from cotton bollworm oral secretion impairs host plant defense signaling. Proc Natl Acad Sci U S A, 116, 14331-14338.

Chen, W., Shakir, S., Bigham, M., Richter, A., Fei, Z., and Jander, G. (2019) Genome sequence of the corn leaf aphid (Rhopalosiphum maidis Fitch). Gigascience, 8, doi: 10.1093/gigascience/giz033.

Chougule, N.P., Li, H., Liu, S., Linz, L.B., Narva, K.E., Meade, T., and Bonning, B.C. (2013) Retargeting of the Bacillus thuringiensis toxin Cyt2Aa against hemipteran insect pests. Proc Natl Acad Sci U S A, 110, 8465-8470.

Chuang, W.-P., Herde, M., Ray, S., Castano-Duque, L., Howe, G.A., and Luthe, D.S. (2014) Caterpillar attack triggers accumulation of the toxic maize protein RIP2. New Phytol., 201, 928-939.

Chuang, W.-P., Ray, S., Acevedo, F.E., Peiffer, M., Felton, G.W., and Luthe, D.S. (2014) Herbivore cues from the fall armyworm (Spodoptera frugiperda) larvae trigger direct defenses in maize. Mol. Plant Microbe Interact., 27, 461-470. 
Cordero, M.J., Raventós, D., and San Segundo, B. (1994) Expression of a maize proteinase inhibitor gene is induced in response to wounding and fungal infection: systemic woundresponse of a monocot gene. Plant J., 6, 141-150.

Craik, D.J., Daly, N.L., Bond, T., and Waine, C. (1999) Plant cyclotides: A unique family of cyclic and knotted proteins that defines the cyclic cystine knot structural motif. J. Mol. Biol., 294, 1327-1336.

Dancewicz, K., Slazak, B., Kiełkiewicz, M., Kapusta, M., Bohdanowicz, J., and Gabryś, B. (2020) Behavioral and physiological effects of Viola spp. cyclotides on Myzus persicae (Sulz.). J. Insect Physiol., 122, 104025.

Dowd, P.F., Zuo, W.N., Gillikin, J.W., Johnson, E.T., and Boston, R.S. (2003) Enhanced resistance to Helicoverpa zea in tobacco expressing an activated form of maize ribosome-inactivating protein. Journal of Agricultural and Food Chemistry, 51, 35683574.

Erb, M. and Reymond, P. (2019) Molecular Interactions Between Plants and Insect Herbivores. Annu Rev Plant Biol, 70, 527-557.

Fitches, E., Audsley, N., Gatehouse, J.A., and Edwards, J.P. (2002) Fusion proteins containing neuropeptides as novel insect contol agents: snowdrop lectin delivers fused allatostatin to insect haemolymph following oral ingestion. Insect Biochem. Mol. Biol., 32, 16531661.

Fitches, E.C., Bell, H.A., Powell, M.E., Back, E., Sargiotti, C., Weaver, R.J., and Gatehouse, J.A. (2010) Insecticidal activity of scorpion toxin (ButaIT) and snowdrop lectin (GNA) containing fusion proteins towards pest species of different orders. Pest Management Science, 66, 74-83.

Fitches, E.C., Pyati, P., King, G.F., and Gatehouse, J.A. (2012) Fusion to Snowdrop Lectin Magnifies the Oral Activity of Insecticidal $\omega$-Hexatoxin-Hvl a Peptide by Enabling Its Delivery to the Central Nervous System. PLoS ONE, 7, e39389.

Food and Agriculture Organization of the United Nations (2018) Integrated management of the fall armyworm on maize: a guide for farmer field schools in Africa.

Goergen, G., Kumar, P.L., Sankung, S.B., Togola, A., and Tamò, M. (2016) First Report of Outbreaks of the Fall Armyworm Spodoptera frugiperda (J E Smith) (Lepidoptera, Noctuidae), a New Alien Invasive Pest in West and Central Africa. PLoS ONE, 11, $\mathrm{e} 0165632$.

Guo, J., Qi, J., He, K., Wu, J., Bai, S., Zhang, T., et al. (2019) The Asian corn borer Ostrinia furnacalis feeding increases the direct and indirect defence of mid-whorl stage commercial maize in the field. Plant Biotechnol J, 17, 88-102.

Hamshou, M., Shang, C., Smagghe, G., and Van Damme, E.J.M. (2016) Ribosome-inactivating proteins from apple have strong aphicidal activity in artificial diet and in planta. Crop Protection, 87, 19-24.

Head, G.P., Carroll, M.W., Evans, S.P., Rule, D.M., Willse, A.R., Clark, T.L., et al. (2017) Evaluation of SmartStax and SmartStax PRO maize against western corn rootworm and northern corn rootworm: efficacy and resistance management. Pest Manag. Sci., 73, 1883-1899.

Howe, G.A. and Jander, G. (2008) Plant immunity to insect herbivores. Ann Rev Plant Biol, 59, 41-66. 
Huang, F., Qureshi, J.A., Meagher, R.L., Reisig, D.D., Head, G.P., Andow, D.A., et al. (2014) CrylF Resistance in Fall Armyworm Spodoptera frugiperda: Single Gene versus Pyramided Bt Maize. PLoS One, 9.

Huffaker, A. (2015) Plant elicitor peptides in induced defense against insects. Current Opinion in Insect Science, 9, 44-50.

Huffaker, A., Dafoe, N.J., and Schmelz, E.A. (2011) ZmPep1, an ortholog of Arabidopsis elicitor peptide 1, regulates maize innate immunity and enhances disease resistance. Plant Physiol., 155, 1325-1338.

Huffaker, A., Pearce, G., Veyrat, N., Erb, M., Turlings, T.C.J., Sartor, R., et al. (2013) Plant elicitor peptides are conserved signals regulating direct and indirect antiherbivore defense. PNAS, 110, 5707-5712.

Javaid, S., Amin, I., Jander, G., Mukhtar, Z., Saeed, N.A., and Mansoor, S. (2016) A transgenic approach to control hemipteran insects by expressing insecticidal genes under phloemspecific promoters. Sci Rep, 6, 34706.

Khan, M.H., Jander, G., Mukhtar, Z., Arshad, M., Sarwar, M., and Asad, S. (2020) Comparison of in Vitro and in Planta Toxicity of Vip3A for Lepidopteran Herbivores. J Econ Entomol, 113, 2959-2971.

King, G.F. and Hardy, M.C. (2013) Spider-venom peptides: structure, pharmacology, and potential for control of insect pests. Annu. Rev. Entomol., 58, 475-496.

Koiwa, H., Bressan, R.A., and Hasegawa, P.M. (1997) Regulation of protease inhibitors and plant defense. Trends in Plant Science, 2, 379-384.

Koo, A.J.K. and Howe, G.A. (2009) The wound hormone jasmonate. Phytochemistry, 70, 15711580.

Liu, S.-M., Li, J., Zhu, J.-Q., Wang, X.-W., Wang, C.-S., Liu, S.-S., et al. (2016) Transgenic plants expressing the AaIT/GNA fusion protein show increased resistance and toxicity to both chewing and sucking pests. Insect Sci., 23, 265-276.

Livak, K.J. and Schmittgen, T.D. (2001) Analysis of Relative Gene Expression Data Using RealTime Quantitative PCR and the 2- $\triangle \triangle C T$ Method. Methods, 25, 402-408.

Lori, M., van Verk, M.C., Hander, T., Schatowitz, H., Klauser, D., Flury, P., et al. (2015) Evolutionary divergence of the plant elicitor peptides (Peps) and their receptors: interfamily incompatibility of perception but compatibility of downstream signalling. $J$ Exp Bot, 66, 5315-5325.

Luna-Ramirez, K., Skaljac, M., Grotmann, J., Kirfel, P., and Vilcinskas, A. (2017) Orally Delivered Scorpion Antimicrobial Peptides Exhibit Activity against Pea Aphid (Acyrthosiphon pisum) and Its Bacterial Symbionts. Toxins, 9, 261.

Macedo, M.L.R., Oliveira, C.F.R., and Oliveira, C.T. (2015) Insecticidal Activity of Plant Lectins and Potential Application in Crop Protection. Molecules, 20, 2014-2033.

McMullen, M., Frey, M., and Degenhardt, J. (2009) Genetics and biochemistry of insect resistance in maize. In: Handbook of Maize: its Biology (Bennetzen,J.L. and Hake,S., eds), p. 587. New York: Springer.

Mei, Y., Liu, G., Zhang, C., Hill, J.H., and Whitham, S.A. (2019) A Sugarcane mosaic virus vector for gene expression in maize. Plant Direct, 3, e00158.

Mei, Y. and Whitham, S.A. (2018) Virus-Induced Gene Silencing in Maize with a Foxtail mosaic virus Vector. Methods Mol. Biol., 1676, 129-139.

Meihls, L.N., Kaur, H., and Jander, G. (2012) Natural variation in maize defense against insect herbivores. Cold Spring Harbor Symp Quant Biol, 77, 269-283. 
Mulvenna, J.P., Mylne, J.S., Bharathi, R., Burton, R.A., Shirley, N.J., Fincher, G.B., et al. (2006) Discovery of cyclotide-like protein sequences in graminaceous crop plants: ancestral precursors of circular proteins? Plant Cell, 18, 2134-2144.

Nakasu, E.Y.T., Edwards, M.G., Fitches, E., Gatehouse, J.A., and Gatehouse, A.M.R. (2014) Transgenic plants expressing $\omega$-ACTX-Hvla and snowdrop lectin (GNA) fusion protein show enhanced resistance to aphids. Front Plant Sci, 5, 673.

Ni, M., Ma, W., Wang, Xiaofang, Gao, M., Dai, Y., Wei, X., et al. (2017) Next-generation transgenic cotton: pyramiding RNAi and Bt counters insect resistance. Plant Biotechnol. $J ., 15,1204-1213$.

Noonan, J., Williams, W.P., and Shan, X. (2017) Investigation of Antimicrobial Peptide Genes Associated with Fungus and Insect Resistance in Maize. Int J Mol Sci, 18.

Ortiz, E., Gurrola, G.B., Schwartz, E.F., and Possani, L.D. (2015) Scorpion venom components as potential candidates for drug development. Toxicon, 93, 125-135.

Pan, Y., Zhao, S.-W., Tang, X.-L., Wang, S., Wang, X., Zhang, X.-X., et al. (2020) Transcriptome analysis of maize reveals potential key genes involved in the response to belowground herbivore Holotrichia parallela larvae feeding. Genome, 63, 1-12.

Panwar, B.S., Kaur, J., Kumar, P., and Kaur, S. (2018) A novel cry52Cal gene from an Indian Bacillus thuringiensis isolate is toxic to Helicoverpa armigera (cotton boll worm). $J$ Invertebr Pathol, 159, 137-140.

Poretsky, E., Dressano, K., Weckwerth, P., Ruiz, M., Char, S.N., Shi, D., et al. (2020) Differential activities of maize plant elicitor peptides as mediators of immune signaling and herbivore resistance. Plant $J, \mathbf{1 0 4}, 1582-1602$.

R Core Team (2017) R: A Language and Environment for Statistical Computing. Vienna, Austria: R Foundation for Statistical Computing.

Ramsey, J.S., Wilson, A.C., De Vos, M., Sun, Q., Tamborindeguy, C., Winfield, A., et al. (2007) Genomic resources for Myzus persicae: EST sequencing, SNP identification, and microarray design. BMC Genomics, 8, 423.

Rauf, I., Javaid, S., Naqvi, R.Z., Mustafa, T., Amin, I., Mukhtar, Z., et al. (2019) In-planta expression of insecticidal proteins provides protection against lepidopteran insects. Sci Rep, 9, 6745.

Shahidi-Noghabi, S., Van Damme, E.J.M., and Smagghe, G. (2009) Expression of Sambucus nigra agglutinin (SNA-I') from elderberry bark in transgenic tobacco plants results in enhanced resistance to different insect species. Transgenic Res., 18, 249-259.

Shivaji, R., Camas, A., Ankala, A., Engelberth, J., Tumlinson, J.H., Williams, W.P., et al. (2010) Plants on constant alert: elevated levels of jasmonic acid and jasmonate-induced transcripts in caterpillar-resistant maize. J Chem Ecol, 36, 179-191.

Song, J., Liu, H., Zhuang, H., Zhao, C., Xu, Y., Wu, S., et al. (2017) Transcriptomics and alternative splicing analyses reveal large differences between maize lines B73 and Mo17 in response to aphid Rhopalosiphum padi infestation. Front Plant Sci, 8, 1738.

Staswick, P.E., Tiryaki, I., and Rowe, M.L. (2002) Jasmonate response locus JAR1 and several related Arabidopsis genes encode enzymes of the firefly luciferase superfamily that show activity on jasmonic, salicylic, and indole-3-acetic acids in an assay for adenylation. Plant Cell, 14, 1405-1415.

Tabashnik, B.E. and Carrière, Y. (2017) Surge in insect resistance to transgenic crops and prospects for sustainability. Nature Biotechnology, 35, 926-935. 
Tamayo, M.C., Rufat, M., Bravo, J.M., and San Segundo, B. (2000) Accumulation of a maize proteinase inhibitor in response to wounding and insect feeding, and characterization of its activity toward digestive proteinases of Spodoptera littoralis larvae. Planta, 211, 6271.

Togola, A., Meseka, S., Menkir, A., Badu-Apraku, B., Boukar, O., Tamò, M., and Djouaka, R. (2018) Measurement of Pesticide Residues from Chemical Control of the Invasive Spodoptera frugiperda (Lepidoptera: Noctuidae) in a Maize Experimental Field in Mokwa, Nigeria. Int J Environ Res Public Health, 15.

Tzin, V., Fernandez-Pozo, N., Richter, A., Schmelz, E.A., Schoettner, M., Schaefer, M., et al. (2015) Dynamic maize responses to aphid feeding are revealed by a time series of transcriptomic and metabolomic assays. Plant Physiol, 169, 1727-1743.

Tzin, V., Hojo, Y., Strickler, S.R., Bartsch, L.J., Archer, C.M., Ahern, K.R., et al. (2017) Rapid defense responses in maize leaves induced by Spodoptera exigua caterpillar feeding. J Exp Bot, 68, 4709-4723.

Ullah, I., Hagenbucher, S., Álvarez-Alfageme, F., Ashfaq, M., and Romeis, J. (2015) Target and non-target effects of a spider venom toxin produced in transgenic cotton and tobacco plants. Journal of Applied Entomology, 139, 321-332.

Van Damme, E.J.M., Zhang, W., and Peumans, W.J. (2004) Induction of cytoplasmic mannosebinding jacalin-related lectins is a common phenomenon in cereals treated with jasmonate methyl ester. Commun Agric Appl Biol Sci, 69, 23-31.

Vandenborre, G., Smagghe, G., and Van Damme, E.J.M. (2011) Plant lectins as defense proteins against phytophagous insects. Phytochemistry, 72, 1538-1550.

Vila, L., Quilis, J., Meynard, D., Breitler, J.C., Marfà, V., Murillo, I., et al. (2005) Expression of the maize proteinase inhibitor (mpi) gene in rice plants enhances resistance against the striped stem borer (Chilo suppressalis): effects on larval growth and insect gut proteinases. Plant Biotechnol. J., 3, 187-202.

Wang, H., Li, S., Teng, S., Liang, H., Xin, H., Gao, H., et al. (2017) Transcriptome profiling revealed novel transcriptional regulators in maize responses to Ostrinia furnacalis and jasmonic acid. PLoS One, 12, e0177739.

Weidmann, J. and Craik, D.J. (2016) Discovery, structure, function, and applications of cyclotides: circular proteins from plants. J. Exp. Bot., 67, 4801-4812.

Yang, L., Gao, J., Zhang, Y., Tian, J., Sun, Y., and Wang, C. (2020) RNA-Seq identification of candidate defense genes by analyzing Mythimna separata feeding-damage induced systemic resistance in balsas teosinte. Pest Manag Sci, 76, 333-342.

Yang, S., Pyati, P., Fitches, E., and Gatehouse, J.A. (2014) A recombinant fusion protein containing a spider toxin specific for the insect voltage-gated sodium ion channel shows oral toxicity towards insects of different orders. Insect Biochemistry and Molecular Biology, 47, 1-11.

Yao, J.H., Zhao, X.Y., Liao, Z.H., Lin, J., Chen, Z.H., Chen, F., et al. (2003) Cloning and molecular characterization of a novel lectin gene from Pinellia ternata. Cell Research, 13, 301-308.

Zacharias, D.A., Violin, J.D., Newton, A.C., and Tsien, R.Y. (2002) Partitioning of lipidmodified monomeric GFPs into membrane microdomains of live cells. Science, 296, 913916. 
bioRxiv preprint doi: https://doi.org/10.1101/2021.01.13.425472: this version posted January 13,2021 . The copyright holder for this preprint (which was not certified by peer review) is the author/funder, who has granted bioRxiv a license to display the preprint in perpetuity. It is made available under aCC-BY 4.0 International license.

Zhang, Y., Huang, Q., Pennerman, K.K., Yu, J., Liu, Z., Guo, A., and Yin, G. (2016) Datasets for transcriptomic analyses of maize leaves in response to Asian corn borer feeding and/or jasmonic acid. Data Brief, 7, 1010-1014.

Zhu, F., Zhou, Y.-K., Ji, Z.-L., and Chen, X.-R. (2018) The Plant Ribosome-Inactivating Proteins Play Important Roles in Defense against Pathogens and Insect Pest Attacks. Front. Plant Sci., 9. 
Table 1. Insect resistance genes that were tested in maize by transience expression using Sugarcane mosaic virus

\begin{tabular}{lllll} 
Source species & Gene name & GenBank ID & MaizeGDB ID & Description \\
\hline Zea mays & Pep1 & XM_008670579 & GRMZM2G055447 & Peptide elicitor 1 \\
\hline Zea mays & Pep3 & XM_008670581 & GRMZM2G339117 & Peptide elicitor 3 \\
\hline Zea mays & JAR1a & NM_001174342 & GRMZM2G091276 & Jasmonate-isoleucine conjugating enzyme \\
\hline Zea mays & JAR1b & NM_001361064 & GRMZM2G162413 & Jasmonate-isoleucine conjugating enzyme \\
\hline Zea mays & RIP2 & NM_001137489 & GRMZM2G119705 & Ribosome-inactivating protein 2 \\
\hline Zea mays & JAC1 & NM_001148875 & GRMZM2G050412 & Jacalin 1, maize lectin \\
\hline Zea mays & AMP & NM_001371023 & GRMZM2G032198 & Cyclotide antimicrobial peptide \\
\hline Zea mays & MPI & X78988 & GRMZM2G028393 & Maize proteinase inhibitor \\
\hline Allium cepa & ACA & DQ255944 & & Onion lectin \\
\hline Galanthus nivalis & GNA & M55556 & & Snowdrop lectin \\
\hline Hadronyche versuta & Hvt & AJ938032 & & w-hexatoxin-Hv1a, spider venom toxin \\
\hline Urodacus yaschenkoi & UyCT3 & JX274241 & & Scorpion venom toxin, antimicrobial peptide \\
\hline Urodacus yaschenkoi & UyCT5 & JX274242 & & Scorpion venom toxin, antimicrobial peptide \\
\hline
\end{tabular}


(a) Spodoptera frugiperda

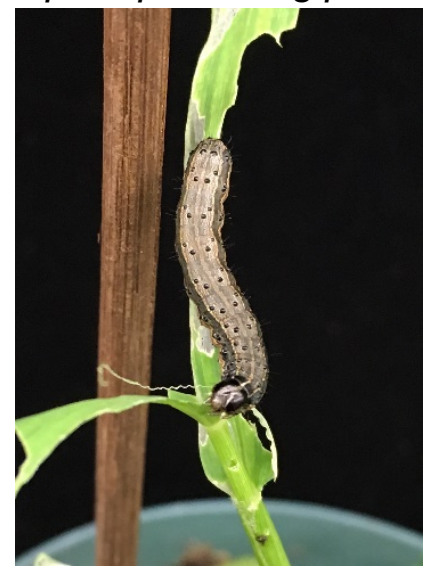

(b) Rhopalosiphum maidis

(c) Myzus persicae
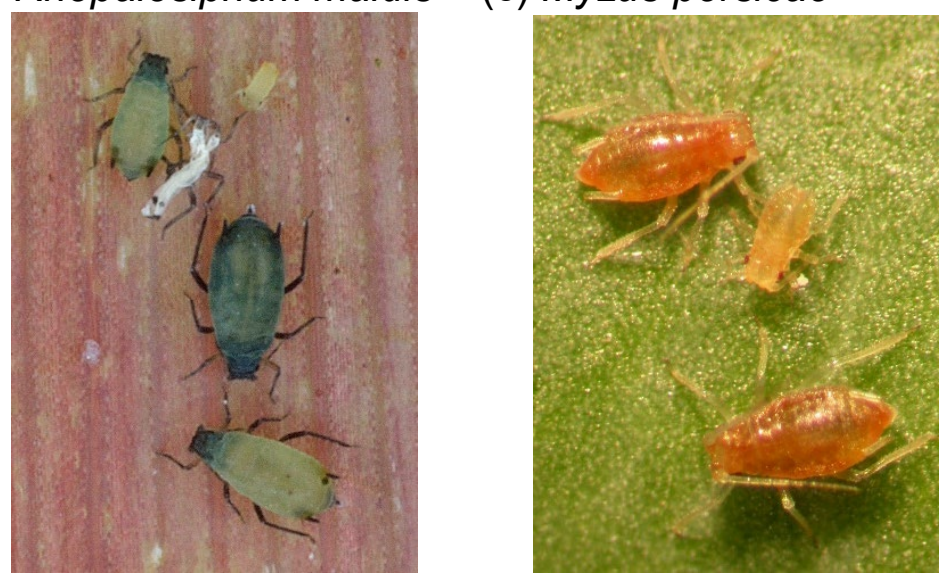

Figure 1. Insect species used in this study. (a) Spodoptera frugiperda, fall armyworm, (b) Rhopalosiphum maidis, corn leaf aphid, (c) Myzus persicae, green peach aphid. 
(a)

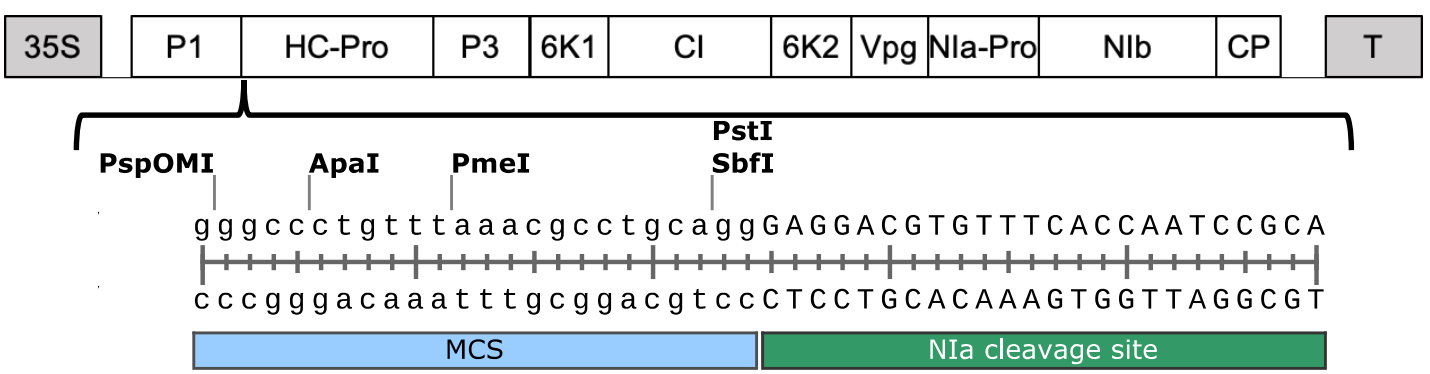

(b)

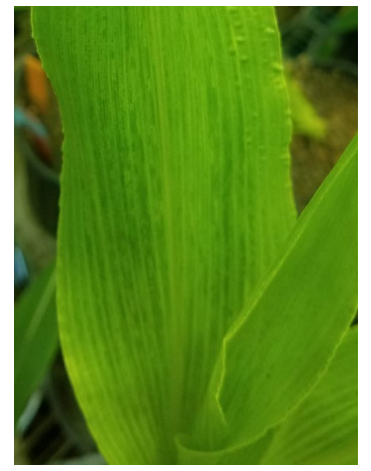

(c)

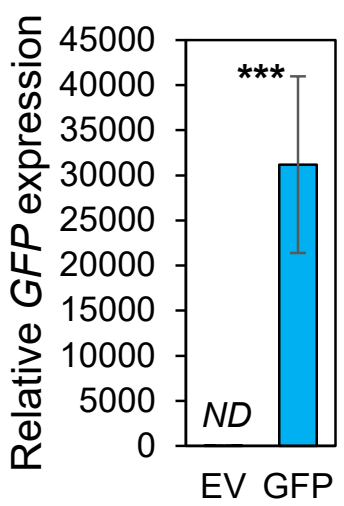

(d)

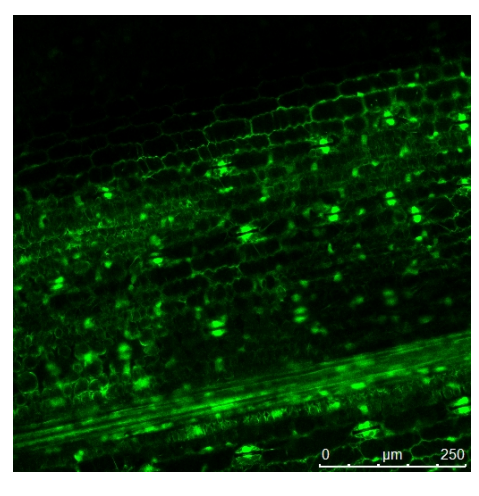

(e)

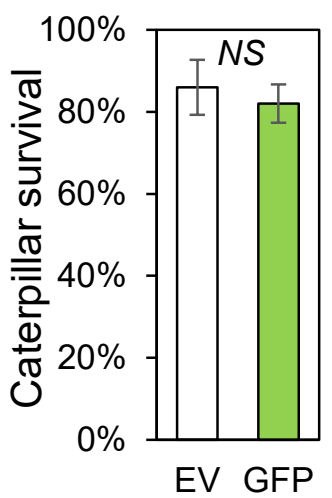

(f)

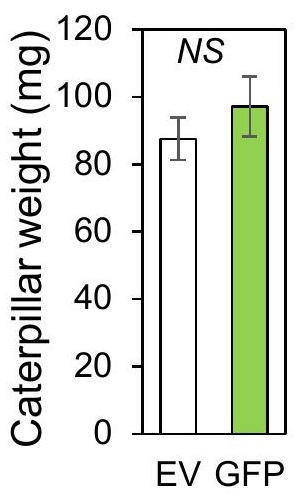

Figure 2. Use of a sugarcane mosaic virus (SCMV) to transiently express GFP in maize. (a) Schematic diagram of the SCMV-CS3 cloning vector. A multiple cloning site (MCS) was inserted between P1 and HC-Pro genes of SCMV. 35S: cauliflower mosaic virus 35S promoter; T: NOS terminator. (b) Mosaic infection symptom of SCMV vector in maize three weeks post inoculation. (c) Transient overexpression of GFP in plants infected by SCMV-empty vector (EV) or -GFP. Gene expression was determined by qRT-PCR three weeks post-inoculation. Means $+/$ - s.e. of $\mathrm{N}=5$, $* * * \mathrm{P}<0.001, t$-test. (d) Confocal image of foliar GFP expression. (e, f) $S$. frugiperda survival and larval growth on plants infected by EV or SCMV-GFP. Two-day-old caterpillars were fed on infected plants for one week and caterpillar mass was determined. Means + s.e. of $\mathrm{N}=10, N S=$ non-significant, $N D=$ not detected, $\mathrm{EV}=$ empty vector, $\mathrm{MCS}$ $=$ multiple cloning site. 
(a) UyCT3

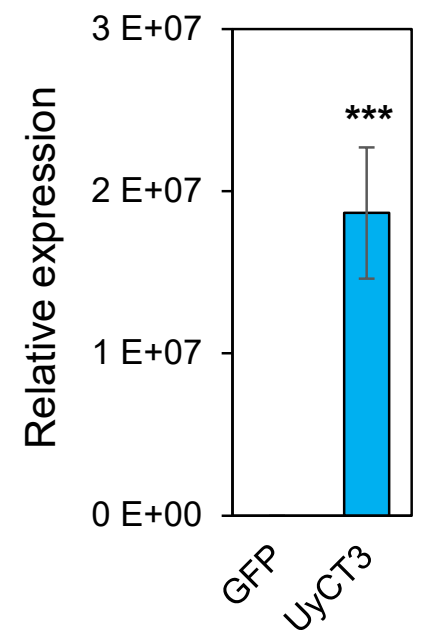

(b) UyCT5

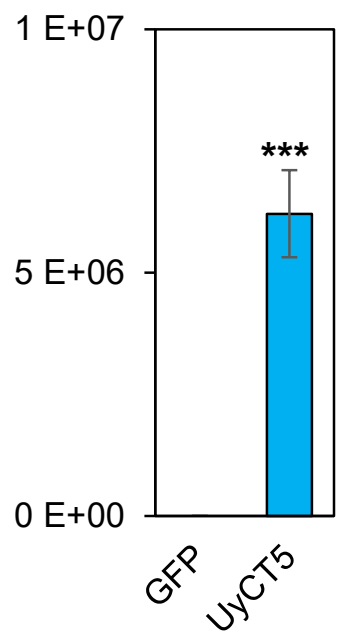

(c) P39

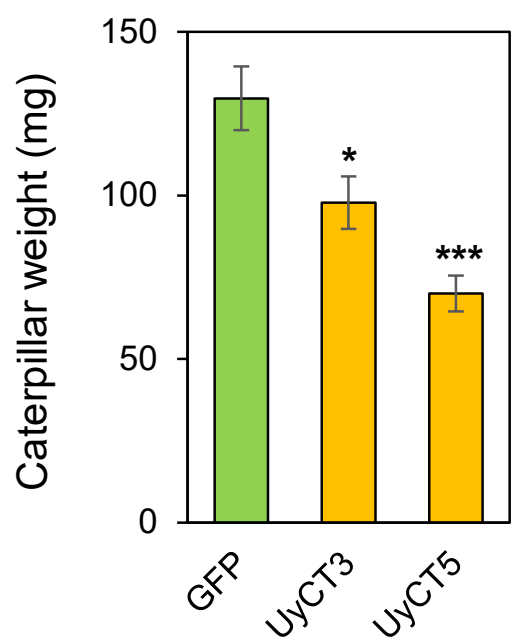

(d) B73

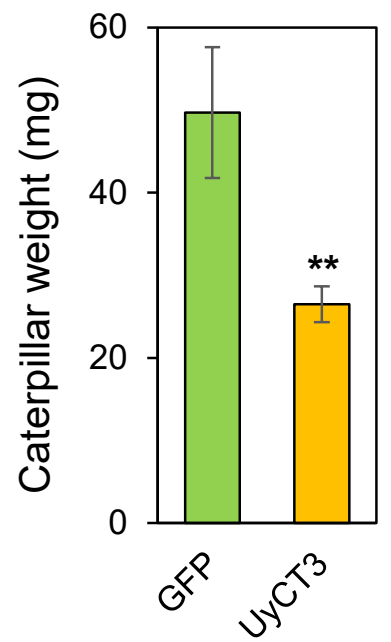

Figure 4. Gene expression and larval growth on P39 plants expressing heterologous insecticidal genes. (a, b) Transient overexpression of UyCT3 and UyCT5 in P39 plants infected by SCMV-GFP, -UyCT3 or UyCT5. Gene expression was determined by qRT-PCR there weeks post inoculation. (c) The performance of $S$. frugiperda on P39 plants expressing GFP, UyCT3 or UyCT5. (d) The performance of S. frugiperda on B73 plants expressing GFP or $U y C T 3$. Five caterpillars were confined on infected plants three weeks post inoculation. Caterpillar weight was measured one week later. Means $+/$ - s.e. of $\mathrm{N}=5$ for gene expression; $\mathrm{N}=7-14$ for insect bioassays, ${ }^{*} \mathrm{P}<0.05 ; * * \mathrm{P}<0.01 ; * * * \mathrm{P}<0.001$ relative to GFP control, Dunnett's test. 
(a) Rhopalosiphum maidis

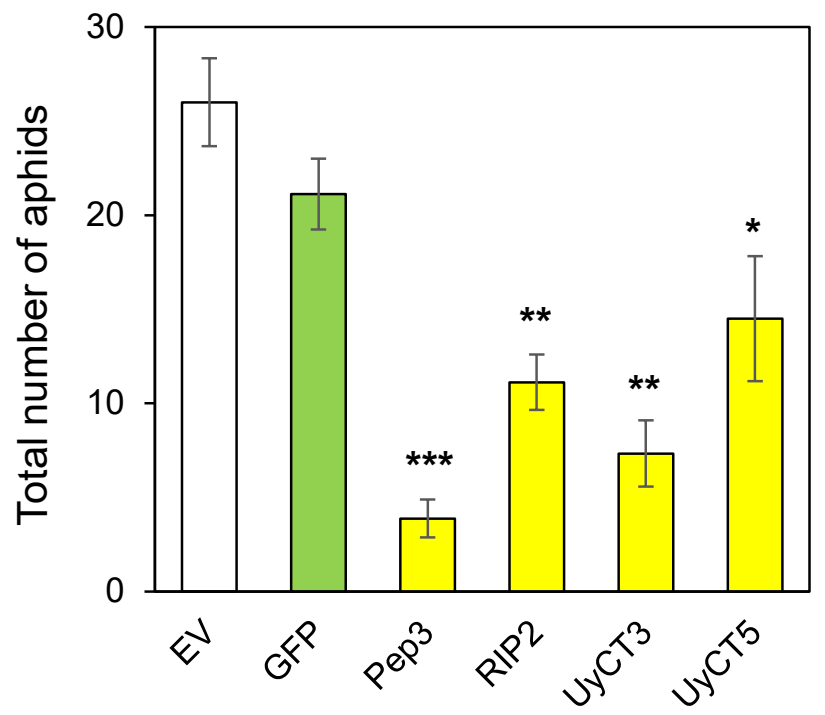

(c) Rhopalosiphum maidis

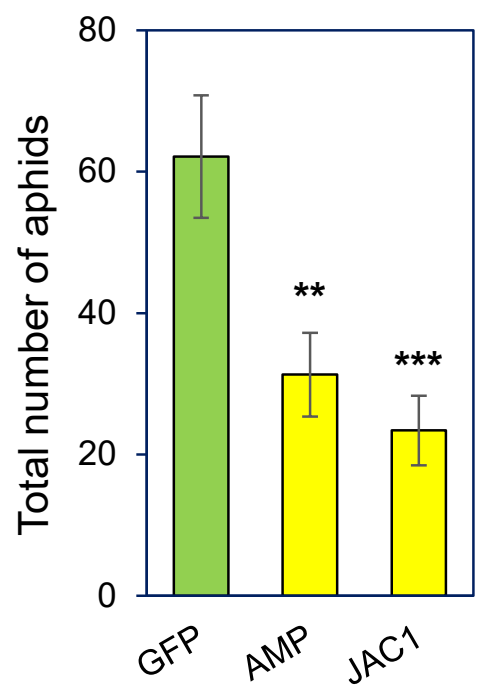

(b) Myzus persicae

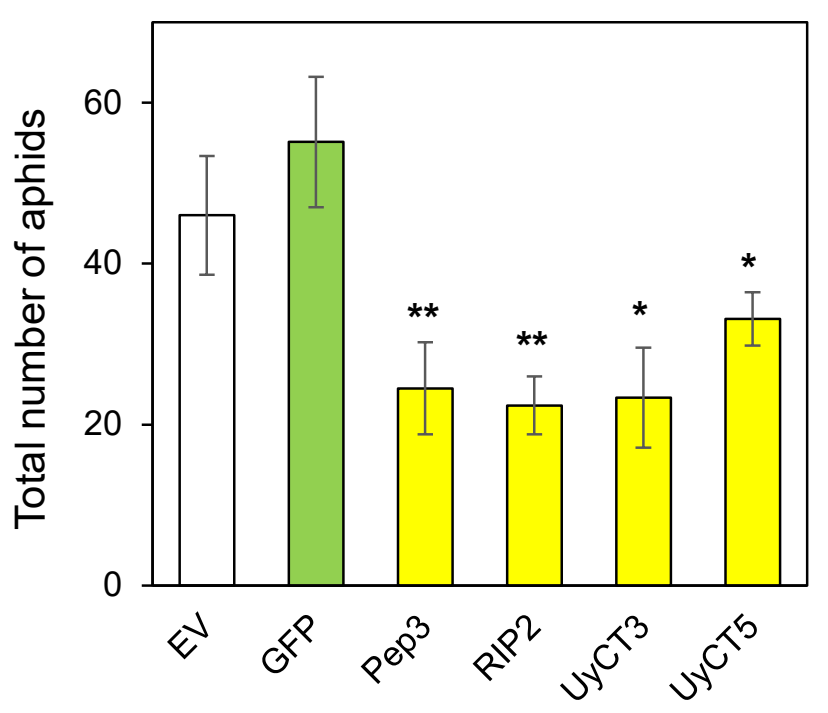

(d) Myzus persicae

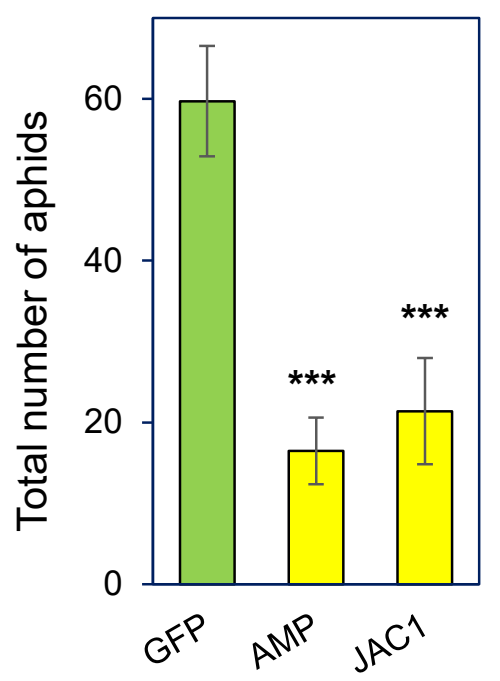

Figure 6. Total number of aphids on P39 plants expressing maize defense genes and scorpion toxin genes. (a,c) Rhopalosiphum maidis (b,d) Myzus persicae. Eight $R$. maidis adults or ten $M$. persicae adults were confined on plants infected by SCMV-EV, -GFP, -Pep3, -RIP2, -UyCT3, $U y C T 5$, AMP or JAC1 three weeks post inoculation. Surviving aphids and their progeny were counted one week later. Means $+/-$ s.e. of $\mathrm{N}=8-10,{ }^{*} \mathrm{P}<0.05 ; * * \mathrm{P}<0.01 ; * * \mathrm{P}<0.001$ relative to GFP control, Dunnett's test. 
(a) $A M P$

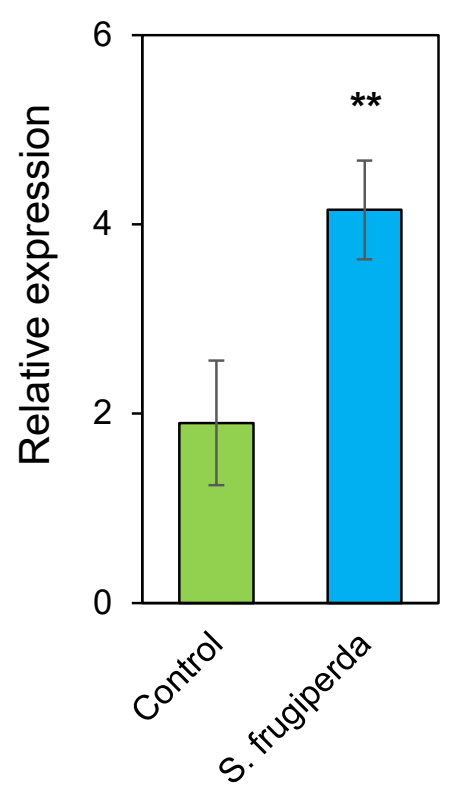

(b) JAC1

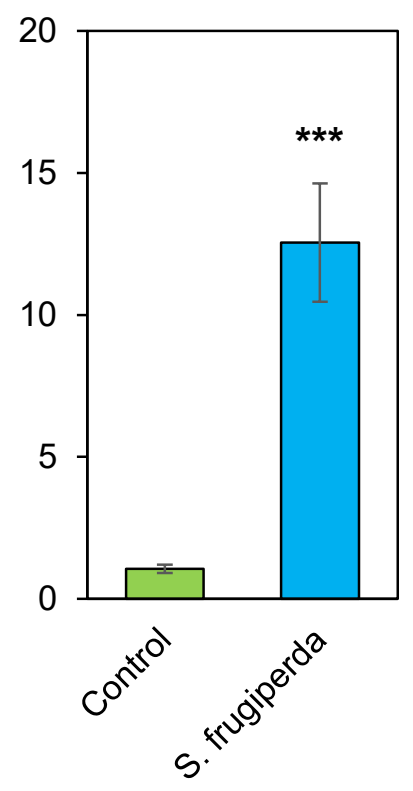

Figure S1. Gene expression of (a) $A M P$ and (b) $J A C 1$ in P39 maize plants damaged by Spodoptera frugiperda caterpillars. Two caterpillars were confined on plants. Gene expression was determined by qRT-PCR one day after placing the caterpillars. Means $+/$ - s.e. of $\mathrm{N}=6, * * \mathrm{P}<$ $0.01 ; * * * \mathrm{P}<0.001$ relative to GFP control, $t$-test. 